This is the post print version of the article, which has been published in Journal of marketing theory and practice . 2017, 25(4), 340-356.http://dx.doi.org/10.1080/10696679.2017.1345593.

Accepted manuscript (accepted on 17.4.2017):

Pihlaja, J., Saarijärvi, H., Spence, M.T. \& Yrjölä, M. (forthcoming). From Electronic WOM to Social WOM - Bridging the Trust Deficit.

\title{
Title: From Electronic WOM to Social eWOM: Bridging the Trust Deficit
}

The purpose of this study is to identify and uncover characteristics of social electronic word-of-mouth. Social eWOM applies to social media platforms in which membership is restricted and content providers are known to recipients. In relation to traditional eWOM platforms that post anonymous reviews, social eWOM has several unique characteristics: intended audience, information trustworthiness, source evaluation, and interpersonal relationships. Therefore, social eWOM should be regarded as conceptually different from anonymous eWOM, with the two serving as endpoints on a continuum. Marketing managers should understand the distinct role and value-creating potential of social eWOM in relation to other forms of WOM and that social media strategies should consider methods for converting anonymous eWOM into social eWOM.

Keywords: word-of-mouth, electronic word-of-mouth, social electronic word-of-mouth, social media, trust 
Purchasing a good or service inherently has an element of risk — anticipated consumption dissatisfaction - that naturally some consumers wish to mitigate (Wulff et al. 2015). The web has emerged as a powerful platform for reducing this risk because consumers can obtain relevant product- and/or firm-related information from other consumers for decision-making purposes (Simonson and Rosen 2014). According to Nielsen (2012), 93 \% of consumers trust product- and service-related information that comes from a person that they know, $70 \%$ trust anonymous peer reviews, and $47 \%$ trust company advertising. There is ample empirical support for why word-of-mouth information from a person the recipient knows is more beneficial than its anonymous counterpart or company advertising (Bone 1995; Brown et al. 2007; Cheung, Lee and Rabjohn, 2008; Schindler and Bickart 2012; Cheung, Anitsal and Anitsal 2007; Cheung et al. 2009), which is why it is imperative in today's interconnected world that marketing managers understand the pros and cons of consumer-to-consumer (C2C) web-hosted forums, review sites, and other forms of social media that facilitate electronic word-of-mouth (eWOM). Compared to marketer-initiated communications, traditional WOM is characterized as face-to-face; is imbued with social context cues; has the potential for interactivity; is likely to stem from a strong-tie, homophilous relationship; and is perceived as less biased, and thus more trustworthy (Brown and Reingen 1987). However, these characteristics do not all apply to electronic word-ofmouth (eWOM). eWOM can be scalable, available to unknown, socially distant recipients, asynchronous, long-lived, and anonymous. Thus, the appropriateness of treating eWOM like traditional WOM has been challenged (Brown et al. 2007; Goldsmith and Horowitz 2006; Hennig-Thurau et al. 2004; Kimmel and Kitchen 2014).

Because the number of consumers seeking online reviews has vastly increased (TripAdvisor, 2016, for example, boasts of 340 million unique monthly visitors), it is imperative to shed light on the implementation and consequences of electronically 
transmitted WOM. For example, a deleterious consequence of anonymous online postings is that nefarious behaviors have emerged, such as manipulating product reviews (Mayzlin et al. 2012). Not surprisingly, this behavior undermines trust, a key element of traditional WOM (Xie et al. 2011). Consumer trust is a critical issue in many domains of online business (Hajli and Khani 2013). The reverse, distrust, is a major cause of e-commerce failures (Jones and Leonard 2008). Given Nielsen's (2012) findings, social electronic word-of-moth (social eWOM), that is, WOM transmitted on social media platforms in which membership is restricted and the content providers are known to recipients, should be perceived as more trustworthy than anonymous peer review postings, such as those available on Tripadvisor.com. As consumers' interconnectedness increases, every contributor can affect the intensity and meaning of the original message (Hennig-Thurau et al. 2013a), which, in turn, can affect product sales (Rui et al. 2013), a company's market value (Bollen et al. 2011), and even trust in the original message (Hajli and Khani 2013).

Despite what would appear to be the obvious advantage of eWOM transmitted within consumers' own social network compared to its anonymous counterpart, this emerging phenomenon has remained relatively underexplored, especially when compared to anonymous eWOM. Authors have acknowledged the need to differentiate social eWOM from other kinds of WOM (Liang et al. 2011-2012; Hennig-Thurau et al. 2013a; Yadav et al. 2013). The impact of social eWOM is not well understood, but it affects patterns of diffusion (Hennig-Thurau et al. 2013b; Simonson and Rosen 2014). Studies by Steffes and Burgee (2009) and Chu and Kim (2011) are steps to fill this gap. Both studies have demonstrated how eWOM in a social context is influenced by homophily, tie strength and interpersonal influence. Nevertheless, more work is needed to explore the differences between anonymous eWOM and social eWOM in order to develop a more precise definition for social eWOM, a precondition for further theory development (Liang et al. 2011-2012). The present research 
effort aims to rectify this shortcoming and contribute to the emerging literature on social eWOM. More precisely, the purpose of this article is to identify and uncover unique characteristics of social eWOM compared to anonymous eWOM. Shedding light on how social eWOM is different from anonymous eWOM will not only help scholars and practitioners differentiate social eWOM from other forms of eWOM, but also provide insight into how to harness the potential of social eWOM.

We start by reviewing relevant literature on eWOM, in which several broad observations are made about social eWOM, albeit there is little direct literature on the latter to draw upon. We then embrace an interpretivist research paradigm, remaining open to discovering new insights. Exploratory research using a case example is presented that unearths consumers' perceptions of social eWOM. Three complementary data collection techniques were employed: verbal protocols, semi-structured interviews, and focus groups. From these, we compare and contrast social eWOM and eWOM, as well as propose a definition of social eWOM. We conclude by advancing managerially relevant issues regarding implementing social eWOM, as well as identifying opportunities for future research.

\section{CONCEPTUAL BACKGROUND}

The revolution in the amount, type, and purpose of customer data is reshaping the nature of markets and marketing. Data about what, where, and when consumers buy; how they buy; who they are; why they buy; and what they say about their purchases are becoming increasingly available to firms and fellow consumers (Edelman 2010). In the online environment, $\mathrm{C} 2 \mathrm{C}$ interactions, social commerce, and modern applications (apps) increase the opportunities that this wealth of data represents. This volume of data is increasing 
exponentially—so rapidly that $90 \%$ of the current data in the world has been created during the last two years (IBM 2015). Collecting, coordinating, managing, and, importantly, deriving value from these data have become a necessity for firms in the contemporary landscape, whether they want to or not (Saarijärvi et al. 2013).

The powerful influence that WOM has on decision-making processes was identified five decades ago (Arndt 1967; Brown and Reingen 1987); its online counterpart, eWOM, has since emerged as a major research topic that includes: the effect of eWOM on sales (You et al., 2015), eWOM's influence on consumers' purchase decision processes (Cheung and Thadani 2012), consumers' response to negative WOM (DeCarlo, Laczniak, Motley and Ramaswami 2007; Pan and Chu 2011), and consumers' motivation to provide eWOM (Hennig-Thurau et al. 2004; Jeong and Jang 2011; Wirtz an Chew 2002). eWOM is defined as "all informal communications directed at consumers through Internet-based technology related to the usage or characteristics of particular goods and services, or their seller" (Litvin et al. 2008, p. 461). Jeong and Jang (2011, p. 356) observed that "eWOM extends customers' choices for gathering information about products and services from other customers." eWOM can be transmitted on various platforms, such as online product review sites, company websites, bulletin boards, blogs, and social networking sites (Cheung et al. 2009). With few exceptions, studies to date do not consider platform differences when researching eWOM. Studies that have explored the effect of different platforms, such as Lee and Youn (2009) and Xue and Phelps (2004), did not find that platform type affected product judgments, which lends support for treating all eWOM as similar. However, in these two studies a common characteristic across the platforms examined was that the eWOM was anonymous. Social eWOM is not anonymous.

eWOM differs from traditional WOM in several important dimensions. Because eWOM is Internet-based versus face-to-face, some of the richness or vividness, such as that 
from body language, is lost; the social distance is greater; eWOM is asynchronous and can be one-to-many rather than one-to-one; and because eWOM is housed on the Internet it is typically not time bound and can be available for long periods (Jeong and Jang 2011). However, similar to traditional WOM, a benefit of eWOM is that it is generated by consumers and thus is perceived as less biased compared to marketer-controlled information (Bickart and Schindler 2001). Thus, eWOM provides consumers with additional information they can use in their various value-creating (Gruen et al. 2006) or purchase risk mitigation decision processes (Smith et al. 2005; Wulff et al. 2015).

Despite the apparent benefits of eWOM, negative effects have been flagged, such as non-response bias. Hu et al. (2009) found that online ratings in Amazon.com tended to be bimodal with many positive ratings, some negative ratings, and few in between. Moreover, recent examples have challenged the veracity of the content itself. For example, authors have written positive reviews for their own books on Amazon.com (Charman-Anderson 2012). Similarly, TripAdvisor, a provider of travel-related reviews, was fined for failing to adopt adequate measures to prevent false reviews while simultaneously promoting itself as "authentic and genuine" (CNBC 2014). Specifically, TripAdvisor was criticized for its policy of letting anyone write reviews regardless of whether the person in question had in fact ever experienced the reviewed service or not (Dodson 2007; McCartney 2012). Due to proven attempts to manipulate reviews and that consumers can use aliases when posting reviews (Mayzlin et al. 2012), the credibility of the reviews can waver (Xie et al. 2011; Pan and Chiou 2011). If trust in online user-generated content is undermined, then the potential benefits of providing online consumer reviews are compromised. Trust, a critical term relevant to this discussion, has been used loosely by various researchers and measured different ways. Key differences in the various definitions are whether trust refers to the veracity of the information (Dean and Biswas 2001), the user's willingness to use the 
information (Chu and Kim 2011), or both (McKnight et al. 2004). Steffes and Burgee (2009, p. 43) observed, "The very nature of eWOM highlights the important theoretical issues of source credibility and user trust."

What consumers are ultimately after is helpful information that will facilitate their decision-making processes. Given the amount of eWOM available, consumers' own evaluation of the worth of eWOM is particularly germane (Steffes and Burgee 2009). Li et al. (2013) provide empirical support that product review helpfulness is a formative construct driven by source credibility (the extent to which those posting comments are deemed trustworthy), content diagnosticity (the ability to distinguish between options), and vicarious expression (how vividly the experience is conveyed). Anonymous eWOM can fail to meet these criteria. However, social media platforms have been developed to increase the truthfulness and richness of eWOM. For example, consumers can create or join closed social groups or networks. In these closed networks it is reasonable to assume that social ties are stronger and that members have a shared identity with the topic at hand and fellow users (homophily). The frequency of interactions and the quantity of information exchanged increase with tie strength (Brown and Reingen 1987). Brown et al. (2007; see also Xie et al. 2011; Hung and Li 2007; and Pan and Chiou 2011, all of whom used hypothetical scenarios and fictitious individuals) found that tie strength and homophily positively affected source credibility. These findings are consistent with McKnight et al.'s (2004, p. 2) proposal that "trust varies by stage of interaction ... as the parties gain familiarity with and information about each other, trust is increasingly based on the direct experience of the trustor with the trustee."

We conjecture that knowing the content provider confers a benefit not possible with content provided by anonymous sources: it could affect how much value or weight the receiver places on the information. Although a content user may perceive a sender's posting 
as an accurate rendition of his or her beliefs (trustworthy), knowledge about the sender may cause a recipient to adjust how much weight to place on the information. For example, information provided by a colleague known to be a budget traveler who extolls the virtues of a particular locale may be significantly discounted by a traveler seeking a luxurious travel experience. Thus, truthful content may or may not be diagnostic in that it serves to discriminate between choice alternatives. Li et al. (2013) found empirical support for trustworthiness and diagnosticity being separate constructs, but in that study, diagnosticity referred to the ability to differentiate products based on performance characteristics discussed within the message, not to the value of the information for the recipient given knowledge about the sender.

Closed networks need not be small. For example, Ugander et al. (2011) found that on Facebook, which then had 721 million active users, the median number of friends one had was 100 , albeit the distribution was skewed so the average number of friends was 190 . In open eWOM platforms, such as anonymous product review websites, the number of recipients can increase by orders of magnitude. The influence of eWOM does not, however, increase in step with the number of individuals within the network as many users are not actively engaged (Kimmel and Kitchen 2014). Similar to a marketing campaign, how attention grabbing the message is will affect its impact. One is more likely to pay attention to messages from strong- versus weak-tie relationships. Naturally, social distance is greater when postings come from anonymous eWOM compared to closed networks, although weaktie relationships have the potential advantage of exposing recipients to a broader pool of opinions, including opinions on topics one's friends may know little about (Steffes and Burgee 2009). Early studies on WOM found a positive relationship between tie strength, WOM propagation, and the influence that WOM has on decision-making (Brown and Reingen 1987). However, two recent studies that explored the effect of social ties in eWOM 
settings yielded contradictory results (compare Chu and Kim 2011, with Steffes and Burgee 2008). Steffes and Burgee (2008, p. 56) found, contrary to their expectations, a negative relationship between tie strength and influence, and proposed that "the anonymous, nonexistent tie source of information can become a weak or perhaps eventually strong tie relationship over time. One would expect that eWOM from strong ties sources would be particularly influential." McKnight et al. (2004) proposed that trust increases with familiarity.

What closed networks gain in the quality of the content (greater trust in the source and the likelihood that product or firm reviews are richer or more vivid) they lack in quantity. Thus, we conjecture that social eWOM and anonymous eWOM are different forms of eWOM from the consumers' point of view. At one end of the continuum is content generated by known sources within the consumer's own social network(s), and at the other end are numerous examples of online reviews that are completely anonymous. Liang et al. (20112012) even suggest different terms should be used.

Despite an emerging body of eWOM-related research, there is a paucity of research investigating how consumers use their own online social networks (social eWOM) for decision-making purposes. Further insight regarding the differences between social eWOM and anonymous eWOM, and the extent, if any, that they differentially affect decision-making is necessary to establish whether they are independent constructs or conceptually different but serve as end points on a continuum. Naturally, social eWOM and anonymous eWOM may share overlapping features (e.g., the types of eWOM are web enabled). Firms can support multiple platforms.

Given the limited research to date specifically directed toward social eWOM, what follows is an exploratory study to discover how consumers actually use and regard social eWOM. In the words of Yadav (2010, p. 2), the aim is the "[c]onception of new ideas (e.g., 
new constructs) or creative synthesis of existing ideas (e.g., new relationships between wellaccepted constructs)."

\section{METHODOLOGY}

The study followed a case study research methodology. Using an illustrative example is an accepted way to illuminate characteristics relevant to a research phenomenon (Nordin and Kowalkowski 2010; Rubalcaba et al. 2012). Case studies are suitable for new research areas or research areas where existing theory seems inadequate (Eisenhardt 1989). However, the case itself is of secondary interest. Stake (2005, p. 445) noted that the case "plays a supportive role, and it facilitates our understanding of something else." In the present study, methodological choices were designed in accordance with the research purpose (see Figure $1)$.

Place Figure 1 about here

\section{Case Description}

In the selection of an appropriate case study, relevance instead of representativeness was the guiding criterion (Stake 1994). Therefore, focus was placed on identifying a suitable case that shared the fundamental characteristics of social eWOM, and thus was different from anonymous eWOM. A good illustrative example of an online application developed to support consumer decision-making within closed networks is the collaborative effort between TripAdvisor and Facebook. TripAdvisor claims to be the world's largest travel website (TripAdvisor 2016) and since 2000 has provided a platform for consumers to post reviews of 
travel services, hotels, destinations, and sights. Given the experiential nature of travel-related services, they are typically harder to evaluate than products, and thus are contexts in which WOM tends to have a strong effect on decision-making (Wirtz and Chew 2002). Over the past few years, TripAdvisor has integrated its service with online social networks, including Facebook. TripAdvisor is one of Facebook's instant personalization partners, which enables Facebook's user data to be utilized in TripAdvisor accounts (MacManus 2012). Two features stand out in this relationship. First, by using a Facebook application (previously known as "Cities I've visited"), users can submit data about which cities they have visited, what they liked about the cities, and where they would like to go. Second, TripAdvisor is allowed to use this data to enrich its service by converting what would be anonymous reviews into social eWOM by compiling and then presenting information that is restricted to the user's own social network. Thus, consumers receive information (e.g., previously visited destinations, future interests, reviews, and opinions) that is limited to their own social network (see Figure 2). Users of the information know who posted the content.

Place Figure 2 about here

\section{Data Generation}

The data generation process consisted of three complementary methods: verbal protocol method, semi-structured interviews, and focus group discussions. Ten informants were asked to participate in the initial exploratory study, five men and five women (see Appendix 1). Informants were selected by using the researchers' own social networks and asking acquaintances to identify suitable candidates for informants. Informants had to meet 
two criteria: $i$ ) They had traveled abroad during the past year, and ii) the informant was familiar with using TripAdvisor as a source of information when planning a trip. The first requirement was used simply to find informants who had had recent experiences with consuming travel services. The latter was about finding informants who were already familiar with the anonymous content provider version of TripAdvisor (eWOM) who could then be exposed to the social eWOM TripAdvisor/Facebook collaboration. All informants belonged to the young adult age group (18-29 years), the age group considered the largest consumer of social media ( (Duggan and Brenner 2013). The number of informants was found to be adequate as the data started saturating after six interviews.

The informants were asked to conduct a travel-related search using TripAdvisor. The informants were not told beforehand about the content or the nature of the given search task. Before the actual search, each informant was asked to log in to his or her TripAdvisor account by using his or her Facebook username. Then the informant was asked to choose two travel destinations that he or she was not familiar with but which he or she would like to visit. During this search, the informants were exposed to user-generated destination-relevant content (i.e., social eWOM), meaning that information from the travel experiences of the informants' personal social networks was visible. The informants were able to see what people in their social networks had said about the destinations the informants had selected. This is a departure from prior controlled experiments in which tie strength and rapportfactors that affect trust — were explored by manipulating content provided by fictional informants (Smith et al. 2005; Pan and Chiou 2011). In Pan and Chiou's (2011) study, informants were shown hypothetical dialogues between unknown parties, while in Smith et al.'s (2005) experiment informants were given hypothetical peer recommendations with short autobiographical profiles attached to them. 
During this phase, research data were generated using the simultaneous (as opposed to retrospective) verbal protocol method (Crutcher 1994; Kuusela and Paul 2000). This method is especially suitable for exploring how information is perceived and used in consumers' decision-making. When this method is applied, informants are asked to describe aloud what they see and think during the given task. Through verbalization, researchers are able to ascertain what and how informants think (Kuusela et al. 1998). There was no effort or intention to guide consumers' decision-making or impose a pre-conceived theoretical framework. The researchers allowed informants to freely verbalize their decision-making processes; the researchers' only input was to remind the informant to actively verbalize his or her thoughts in the event the informant ceased to talk out loud (Todd and Benbasat 1987). Consequently, the method illuminates the role of specific pieces of information and decision rules used when making decisions (Kuusela et al. 1998; Todd and Benbasat 1987), which is why this method was deemed suitable for investigating the characteristics of social eWOM.

In the second phase of the data generation process, semi-structured interviews were conducted to further explore interesting issues and perspectives that had emerged during the first phase. This allowed the researchers to ask additional, complementary questions, as well as discuss in broader terms how the informants perceived the role of social eWOM in their decision-making. Together, the data from the verbal protocol analysis and the interviews that were recorded and transcribed resulted in approximately 10 hours of data.

Finally, in the third phase, in order to verify the preliminary findings and further explore the phenomenon, four focus group discussions were arranged (see Appendix 2). Participants were recruited through the researchers' networks and the recruitment flyer stated that the discussion would involve online product reviews, recommendations and ratings, and that participants should have at least some experience regarding them. The focus groups consisted of 3-6 participants, thus being within recommendations (Hague et al., 2013). As a 
data generation method, focus groups allowed for probing motivating factors and for informants to raise issues that are personally relevant to them. Issues related to social eWOM were discussed and debated by participants, thus the members themselves collectively made sense of a phenomenon (Lee et al., 2013; Hague et al., 2013).

Focus group discussions were recorded and each lasted approximately 1.5 hours. The focus groups were held with a researcher and an assistant present. The researcher acted as the discussion facilitator, while the assistant took notes. In addition to the recorded transcripts, approximately 20 pages of notes were generated. The discussion began by asking about anonymous online reviews and recommendations. Then, screenshots of the TripAdvisor service were used to stimulate a discussion regarding social eWOM. Later, to explore the role of product category on social eWOM, screenshots of Goodreads.com, a social eWOM platform for books, were shown to the participants. Throughout the focus groups participants were encouraged to identify perceived differences and the relative usefulness of anonymous and social eWOM.

\section{Data Analysis}

The data analysis followed established procedures for content analysis with the aim of enhancing understanding of the research phenomenon and addressing the research purpose, that is, identifying and uncovering characteristics of social eWOM. First, the analysis began with the researchers reading through all the transcriptions and listening to the recorded protocols and interviews. Second, the first author, independent of the others, coded the material focusing on the role of social eWOM in the informants' search for travel information. This resulted in identification of 25 general qualities of social eWOM, albeit there was considerable overlap. Third, the other authors independent of the first author further analyzed the data by using the results from the initial coding. The other authors 
discussed areas of conflict and differences in opinion with the aim of further synthesizing the data. This phase took several iterations because some protocols exhibited multiple qualities. The researchers' goal was to group protocols into a parsimonious, but representative, categorization scheme. When this process was completed, the qualities identified by the first author were refined into 17 social eWOM characteristics that addressed different aspects of social eWOM, for example, how it was used in decision-making and how it was perceived by the informants. Fourth, all the authors together continued with content analysis by exploring the differences and similarities between the identified characteristics. This resulted in grouping the characteristics along four dimensions that capture the defining nature of social eWOM: intended audience, information trustworthiness, evaluation of source, and interpersonal relationships (see Appendix 3 for illustrative quotes that represent the 17 characteristics grouped along the four dimensions). These dimensions and their subsequent characteristics are discussed next and summarized in Table 1. The illustrative quotes that follow are labeled to indicate if they were from the simultaneous verbal protocols (VPs), semi-structured interviews (SSIs), or focus group discussions (FGs)

Place Table 1 about here

\section{RESULTS}

\section{Intended Audience}

The non-public characteristic of social eWOM refers to the fact that it is limited to a restricted social network. In comparison with anonymous eWOM that is broadcast to an 
unknown audience, social eWOM has a clearly intended audience. Because social eWOM is non-public, two benefits were acknowledged by informants. First, as mentioned by informant F4 (female 4 of 5), from the point of view of information searching, it was easier to find relevant information to support their decision-making because the amount and quality of information were more manageable and appropriate.

To some extent, it narrows down information, like, if you think about how much information there is in the world and how much stuff you can look up online. I just have to narrow down the information somehow, like what will I even look for and what kind of places are worth going to for me. It's just such an easy filter that there are people who have traveled there a lot, so you can look up what they have done and then check out more info on what I'm interested in. (F4, SSI)

Second, from the social eWOM provider's perspective, the ability to limit the information to a specific social group or network was also perceived as valuable. The following quote suggests that what someone might post to a closed network is considered by some to be inappropriate to broadcast; the closed network provides some protection. We can only speculate that is unlikely that $\mathrm{K}_{\text {_ }}$, the individual referred to, would have announced his or her imminent departure to an unknown audience.

I don't want people to see everything I've done. I only want them to see the places I want to share and nothing more. I mean so that I can totally use my own judgment, because just now I felt worried about that TripAdvisor, too, that will it show now that $K_{\ldots}$ _ is planning a trip to London. (M3, SSI) 
In the words of these informants, what made social eWOM beneficial and thus different from eWOM was its non-public characteristic. This allowed them to streamline the process of information search and use, as well as provided a level of comfort to providers regarding what was shared and with whom. Although Steffes and Burgee (2009, p. 43) explored an anonymous eWOM context, our insights corroborate their view that "usercentered evaluation of information is particularly germane ... given the volume of user generated information available in the online environment and the ever-growing burden on users to determine its worth."

\section{Information Trustworthiness}

Trustworthiness of the information was identified as another element underpinning the value of social eWOM (Brown and Reingen 1987; Wulff et al. 2015). Because social eWOM stems from individuals known to the receiver, the information is deemed more truthful than when WOM is provided by an anonymous source, consistent with findings by Nielsen (2012). McKnight et al. (2004) argued that trust evolves over time and increases with familiarity between trustor and trustee. Anonymous eWOM lacks the ability to develop familiarity between parties. Truthful in this sense does not necessarily mean the information is helpful, but that the recipient can be confident it is not fabricated. In reference to eWOM, M4 noted that despite the quantity of reviews, because the content was anonymous it had to be deeply discounted prior to decision-making:

You can just ignore $90 \%$ of the reviews [referring to anonymous eWOM]. This reflects what 5,000 idiots have to say about the destination. That's why you always have to look up some information on your own, too. (M4, SSI). 
Social eWOM, in turn, allowed the informants to contact particular individuals and thus engage in collaborative problem solving. The social network acted as a platform for active dialogue directly with the source, a recognized potential benefit of traditional WOM. Interactivity is also likely to enhance "vicarious expression," a defining property of helpful product reviews (Li et al. 2013):

I'll get a reliable source since I can then talk to this person directly without anyone in between. ... Because I know this guy anyway, so he wouldn't dare lie to me at least. (F2, SSI).

For me, the most important thing is that these people act like a kind of a backup. From them I'd ask, for example, about New York, like what are the places I really have to see there. So that I don't miss like one of the must-see spots when I travel all the way there. (M5, SSI)

I guess the thing is that as you know these people personally and see that they stand behind their words, that they've voiced their opinion publicly showing their own name and face ... So somehow you just consider it a more reliable source as they say it out loud, so to speak, showing their own name and face it somehow feels more convincing to me. (FG 1)

I personally feel that I trust my friends' opinions quite a lot. I don't necessarily always share them but I trust them nevertheless, and I'm interested in what they have looked at and would surely browse through them myself, as well. (FG 3)

If I traveled now to Maldives, I'd ask them (friends who have visited there) for advice. (M4, VP). 
In sum, when users extracted information from their own social group or network as opposed to an anonymous review site, they perceived the information as more trustworthy.

\section{Evaluation of the Source}

Social eWOM allows informants to evaluate the source of the information. Despite recipients having high levels of trust in the information provided, having an impression of the source and their personal preferences allows users to adjust how much value or weight to place on the information:

If it's a friend who's written the review, from that I know best because in that case I can kind of assess the review and compare it to this person's style and habits and character. (F1, SSI).

As described by informant M3, knowing that a certain person regularly gives excessively positive reviews resulted in the informant discounting the information provider's content:

I kind of do when I see that one girl. All the places she's been to are rated five stars. I would've known up front that even if she'd take out the garbage she'd rate it five stars. You get the feeling that "yea, right!" If $M$ gave this place five stars, does it really mean anything? (M3, VP).

I think you probably always put the reviews into perspective, in a way, based on who has written them, as you know your family and know their mindset and you know which things they see differently and as for those things their opinion isn't so significant, as opposed to those things you know they think along the same lines as you do. (FG 2) 
Altogether, source evaluation allowed the users to adjust how much value or weight to place on the information on the basis of the source, which is not possible if the content is anonymous. McKnight et al. (2004), in a study involving the effect of third-party assurance seals, found evidence for making the distinction between trustworthy information and trusting intentions, a willingness to rely on the information.

\section{Interpersonal Relationships}

Through social eWOM, the providers and users of the information were able to build and maintain their interpersonal relationships, a benefit not possible when posting or reviewing anonymous content. Information exchanges served a purpose other than facilitating social e-commerce, that is, information sharing to facilitate commercial intentions (Liang et al. 2011-2012). Becoming aware of the different places others have visited, sharing the informants' own experiences, and asking guidance from their network were ways to further develop and enrich existing social ties and relationships. An informant stated:

It's really interesting to see where your friends have been to. It's nice to know who the heavy travelers are and what kind of destinations they go to. Like if a friend of mine travels to some exotic places it tells me something about that person for sure. (F3, SSI)

In addition, social eWOM is used to build one's own identity and to enhance one's social status within the social group or network: 
Generally speaking, the point of social media is to highlight yourself. That's what you do when you share information about yourself. Tell about yourself and then that somehow makes you more familiar to other people. [...] It's just typical Facebooking that you try to show what kinds of things you've done and then kind of boost your own ego while you're at it. (M3, SSI)

On the other hand, maybe this, too, could affect you some way unconsciously. If you see that many of your friends have been to South Africa, so it might occur to you that South Africa is probably quite a nice place if so many have been there. (FG 3)

Oh look at that, I didn't know that also $S_{-}$has traveled that much. (F3, VP)

Thus, exchanging product-related information was not the sole benefit of social eWOM; it serves a purpose other than facilitating social e-commerce. Social eWOM fuels social interactions in ways that anonymous eWOM cannot. Social eWOM shifts the focus beyond the one-way, passive nature of eWOM toward building a better understanding of one's network partners, as well as the possibility of a two-way dialogue (which may occur offline).

\section{DISCUSSION}

The dimensions discussed provide the basis for advancing a definition for social eWOM. We start by again presenting a commonly accepted definition of eWOM: "all informal communications directed at consumers through Internet-based technology related to the usage or characteristics of particular goods and services, or their seller" (Litvin et al. 2008, p. 461). However, the issues identified lie outside this definition emphasizing the 
importance of treating social eWOM as a separate form of eWOM. Thus, we define social eWOM as:

informal, interpersonal communications within a restricted social network related to the usage or characteristics of particular goods and services or their sellers that is deemed more trustworthy by recipients than anonymous postings, serves to develop interpersonal relationships, and is provided in a context in which the receiver knows the content provider, and thus can better interpret or weigh the information given knowledge about the content provider.

This suggests that although social eWOM and traditional anonymous eWOM share common features (e.g., web hosted) and are therefore related, these two types of eWOM are conceptually different. Analogous to acknowledging that there exists a continuum between pure products and pure services, and the differences between them have powerful implications for a firm's marketing strategy, anonymous eWOM and social eWOM serve as endpoints on a continuum and their differences should be considered when developing a social media strategy (Figure 3).

Place Figure 3 about here

Adding the social aspect to eWOM brings new benefits to providers and users of information. Differences between anonymous eWOM and social eWOM are realized in four dimensions. First, anonymous eWOM and social eWOM differ in terms of the target of the information. eWOM is typically thought of as publicly available for anyone to access, whereas social eWOM has an intended and limited audience. For example, posting directly 
on the TripAdvisor website is a one-to-many comment distributed to an anonymous audience (eWOM); however, when in the TripAdvisor/Facebook collaborative version, users provide and consume information within their own social networks. Because the audience is restricted, what providers are willing to post may differ. Further research is required to see if social eWOM mitigates the tendency for anonymous eWOM postings to be bi-modal (Hu et al. 2009). Second, information content validity refers to consumers' ability to evaluate the veracity of the information. The content of anonymous eWOM comes from an unknown source; thus, the truthfulness is difficult to determine. There is published evidence of nefarious eWOM-related behavior (Mayzlin et al. 2012). However, information provided by friends is considered more trustworthy. Nielsen (2012) found that trust regarding product and service information fell from $93 \%$ if one knew the provider of the information to $70 \%$ if it came from an anonymous source. Third, the incentives to share are different in eWOM and social eWOM. For example, the building of interpersonal relationships is an important incentive unique to social eWOM. In social eWOM, interpersonal relationship building is a goal in itself, independent of commercial (social commerce) implications. Finally, information source validity varies between anonymous eWOM and social eWOM. With eWOM, it is difficult if not impossible to be sure who has provided the review (in some eWOM platforms personal information is provided, such as when they experienced the service), whereas with social eWOM the consumer knows the source. Knowing the source is a powerful benefit. While you might believe your friend has been truthful in his or her posting (information content validity noted above), given that you possess knowledge about the provider's personality and/or experience or expertise with the topic at hand, the information can be weighted accordingly when making decisions.

Smith et al.'s (2005) findings suggested that the product category or the consumer's goal (utilitarian or hedonic) affect what type of information is preferred (in their study, editor 
versus peer recommendations) when making decisions. In hedonic categories, such as travel, social eWOM might be preferred to other forms of eWOM: The social relationships within the network facilitate trust in recommendations.

\section{MANAGERIAL IMPLICATIONS}

The number of consumers turning to the web to seek or provide product-related information is increasing exponentially. Some firms address this need by creating websites

and sending out emails. In the absence of a clear social media strategy, Kimmel and Kitchen (2014) labeled such activities "pre social." We argue that marketing managers must understand the pros and cons of web-facilitated $\mathrm{C} 2 \mathrm{C}$ interactions and should take measures to convert anonymous eWOM into social eWOM. The latter is more likely to be attention grabbing and therefore transformative as participants have the opportunity to engage in collaborative problem solving with trusted sources (Kimmel and Kitchen 2014).

From a managerial perspective, instead of managers discussing the relevance of eWOM in general, they should be more precise about what type of eWOM they desire to facilitate and for what purpose (Engleman 2010). Companies need to make a distinction between at least three kinds of eWOM: anonymous eWOM, social eWOM, and emerging hybrids that lie in between (e.g., public discussion forums or news media sites that allow the user to decide whether to comment anonymously or via their Facebook or Twitter profiles). These differ in value-creating potential and should thus be approached differently. eWOM can emerge from many different virtual communities and online platforms. These platforms differ in the media richness of their content (e.g., text, photos, music, videos), their focus (information exchange or social interaction), and their accessibility (open or closed; Kaplan 
and Haenlein, 2010). Further, it is important to appreciate the role of the participant in these different platforms (observer, commenter, or content creator), as well as how participants interact with each other and how much information consumers disclose about themselves. For instance, the influence of social eWOM can be expected to be higher in media-rich platforms that stimulate social interaction and have a high degree of self-presentation. Using these criteria, managers must choose which platforms to invest in. Facebook is a dominant player and Google is developing methods to personalize information search, but new providers that facilitate social networks are constantly entering the market. Converting anonymous eWOM to social eWOM requires investing in infrastructure that enables social eWOM.

Second, managers need to develop clear guidelines for company participation in these different online platforms. At a minimum, companies should monitor product or service discussions, but in some cases companies can encourage discussion or even participate in it, depending on the platform. In closed platforms focused on social interaction consumers might view company participation negatively. On public platforms company responses might be more expected, but the communication has to be direct, showing authenticity and identity. Overall, managers need to acknowledge that to a large extent $\mathrm{C} 2 \mathrm{C}$ interactions are beyond the firm's control and may be very influential when decision making (Simonson and Rosen 2014). Due to the ubiquitous nature of mobile Internet, social eWOM behavior might start simultaneously with the consumption of the product or service, which highlights the need to react to problems immediately.

Third, many companies are already embracing the unique characteristics of social eWOM. For instance, the Amazon-owned book review platform Goodreads lets users log in with their social media profiles so they can share, recommend and view each other's bookshelves. In a music context, Spotify is fully integrated with Facebook to enable users to 
discover what their friends are listening to as well as share playlists. AirBnB is also linked to Facebook which should increase the perceived trustworthiness of user reviews.

Finally, through social eWOM marketing managers can become aware of those consumers who are acting as brand ambassadors and may reward and encourage eWOM behavior, such as rewarding opinion-seeking, -giving, and -sharing behavior (Chu and Kim 2011; Edelman 2010). Gummerus et al. (2012) recommend offering economic rewards (lotteries), entertainment rewards (games), and social benefits (recognition, status) to consumers in exchange for their participation. Combining different rewards with different types of eWOM and platforms might prove to be an effective brand building strategy (e.g., status rewards in relation to social eWOM or entertainment rewards in media-rich platforms). Incentivizing individuals to provide content is widely acknowledged (Hennig-Thurau et al. 2004), but drawing attention to the intrinsic benefit of building and strengthening one's own identity within their peer group is unique to social eWOM.

\section{DIRECTIONS FOR FUTURE RESEARCH}

There are limitations relevant to this study that must be taken into account. Given the explorative nature of this qualitative case-based illustrative example and the sample's restricted age range, the results should not be generalized but rather used to guide future research on eWOM in general and social eWOM in particular. We recommend that future research should consider anonymous eWOM and social eWOM as conceptually different forms of eWOM with each having its unique potential and role in social media strategies. Verbal protocol analysis is a recognized method for unearthing concepts and decision processes relevant to decision-making (Kuusela et al. 1998; Todd and Benbasat 1987); 
however, more research needs to be done to better understand the psychological and emotional reasons why consumers engage in social eWOM. Our resultant definition of social eWOM makes it clear that social eWOM is different from anonymous eWOM. The social eWOM dimensions identified (intended audience, information trustworthiness, interpersonal relationships, and source evaluation) are inter-related and partly overlap. Further investigation may very well reveal additional dimensions. Nonetheless, these dimensions provide valuable insights to marketer practitioners responsible for developing and expanding their firm's social media presence. These dimensions also provide a necessary step toward building a theory regarding how social eWOM affects consumers and their decision-making.

Applications that collect and disseminate consumer provided content are increasingly being developed, making the phenomenon of social eWOM topical, dynamic, and open to further research. Given the insights presented herein, treating all eWOM platforms as equal is inappropriate. There appears much to be gained by individuals and firms creating and using social eWOM platforms.

\section{REFERENCES}

Adjei, Mavis T., Edward L. Nowlin, and Tyson Ang (2016), "The Collateral Damage of C2C Communications on Social Networking Sites: The Moderating Role of Firm Responsiveness and Perceived Fairness," Journal of Marketing Theory and Practice, $24(2), 166-85$.

Arndt, Johan (1967), "Role of Product-Related Conversations in the Diffusion of a New Product, ” Journal of Marketing Research, 4 (3), 291-95.

Bickart, Barbara, and Robert M. Schindler (2001), "Internet Forums as Influential Sources of Consumer Information," Journal of Interactive Marketing, 15 (3), 31-40.

Bollen, Johan, Huina Mao, and Xiaojun Zeng. (2011), "Twitter Mood Predicts the Stock Market," Journal of Computational Science, 2 (1), 1-8.

Bone, Paula Fitzgerald (1995), "Word-of-Mouth Effects on Short-term and Long-term Product Judgements," Journal of Business Research, 32 (3), 213-23. 
Brown, Jacqueline Johnson, and Peter H. Reingen (1987), "Social Ties and Word-of-Mouth Referral Behavior," Journal of Consumer Research, 14 (3), 350-62.

Brown, Jo, Amanda J. Broderick, and Nick Lee (2007), "Word of Mouth Communication Within Online Communities: Conceptualizing the Online Social Network," Journal of Interactive Marketing, 21 (3), 2-20.

Charman-Anderson, Suw (2012), "Fake Reviews: Amazon's Rotten Core," Forbes, August 28 (available at http://www.forbes.com/sites/suwcharmananderson/2012/08/28/fake-reviewsamazons-rotten-core/\#401a3b8666d6).

Cheung, Christy M.K., and Dimple R. Thadani (2012), "The Impact of Electronic Word-ofMouth Communication: A Literature Analysis and Integrative Model," Decision Support Systems, 54 (1), 461-70.

------, Matthew K.O. Lee, and Neil Rabjohn (2008), “The Impact of Electronic Word-ofMouth. The Adoption of Online Opinions in Online Customer Communities," Internet Research, 18 (3), 229-47.

Cheung, Mee-Shew, M. Meral Anitsal, and Ismet Anitsal (2007), "Revisiting Word-of-Mouth Communications: A Cross-National Exploration," Journal of Marketing Theory and Practice, 15 (3), 235-49.

Cheung, Man-Yee., Chuan Luo, Choon Ling Sia, and Huaping Chen (2009), "Credibility of Electronic Word-of-Mouth: Informational and Normative Determinants of Online Consumer Recommendations," International Journal of Electronic Commerce, 13 (4), 9-38.

Chu, Shu-Chuan, and Yoojung Kim (2011), "Determinants of consumer engagement in electronic word-of-mouth (eWOM) in social networking sites," International journal of Advertising, 30 (1), 47-75.

CNBC (2014), “TripAdvisor Fined \$600,000 for Fake Reviews,” December 23 (available at http://www.cnbc.com/id/102292002).

Crutcher, Robert J. (1994), "Telling What We Know: The Use of Verbal Report Methodologies in Psychological Research,” Psychological Science, 5 (5), 241-44.

Dean, Dwane Hal and Abhijit Biswas (2001), "Third-Party Organization Endorsement of Products: An Advertising Cue Affecting Consumer Prepurchase Evaluation of Goods and Services", Journal of Advertising, 30(4), winter, 41-57.

DeCarlo, Thomas E, Russell N. Laczniak, Carol M. Motley, and Sridhar Ramaswami (2007), "Influence of Image and Familiarity on Consumer Response to Negative Word-ofMouth Communication about Retail Entities," Journal of Marketing Theory and Practice, 15 (1), 41-51.

Dodson, Sean (2007), "Best of the Net. Tripadvisor the Great Divide," The Guardian, July 21 (available at http://www.guardian.co.uk/travel/2007/jul/21/saturday.travelwebsites). 
Drucker, Peter Ferdinand (1988), "The Coming of the New Organization," Harvard Business Review, 66 (1), 45-53.

Duggan, Maeve and Joanna Brenner (2013), "The demographics of social media users, 2012," (Vol. 14). Washington, DC: Pew Research Center's Internet \& American Life Project.

Edelman, David C. (2010), "Branding in the digital age", Harvard Business Review, December, 62-69.

Eisenhardt, Kathleen M. (1989), "Building Theories from Case Study Research," Academy of Management Review, 14 (4), 532-50.

Goldsmith, Ronald E., and David Horowitz (2006), "Measuring Motivations for Online Opinion Seeking," Journal of Interactive Advertisement, 6 (2), 2-14.

Gruen, Thomas W., Talai Osmonbekov, and Andrew J. Czaplewski (2006), “eWOM: The Impact of Customer-to-Customer Online Know-How Exchange on Customer Value and Loyalty," Journal of Business Research, 59 (4), 449-56.

Gummerus, Johanna, Veronica Liljander, and Catharina von Koskull (2012), "Customer engagement in a Facebook brand community," Management Research Review, 35 (9), $857-877$.

Hague, P., Hague, N., and Morgan, C-A. (2013). Market Research in Practice - How to Get Greater Insight from your Market. $2^{\text {nd }}$ edition. KoganPage: London.

Hajli, Mohammad, and Farnaz Khani (2013), "Establishing Trust in Social Commerce Through Social Word of Mouth," In e-Commerce in Developing Countries: With Focus on e-Security (ECDC), 2013, April, 7th International Conference on IEEE, 1-22.

Hennig-Thurau, Thorsten, Charles F. Hofacker, and Björn Bloching (2013a), "Marketing the Pinball Way: Understanding How Social Media Change the Generation of Value for Consumers and Companies," Journal of Interactive Marketing, 27 (4), 237-41.

------, Carolyn Wiertz, and Fabian Feldhaus (2013b), "Does Twitter Matter? An Investigation of the Impact of Microblogging Word of Mouth on Consumers' Adoption of New Product," Social Science Research Network (Manuscript available at http://papers.ssrn.com/sol3/papers.cfm?abstract id=2016548.

------, Kevin P. Gwinner, Gianfranco Walsh, and Dwayne D. Gremler (2004), "Electronic Word-of-Mouth via Consumer-Opinion Platforms: What Motivates Consumers to Articulate Themselves on the Internet?," Journal of Interactive Marketing, 18 (1), 38 52.

Hu, Nan, Jie Zhang, and Paul A. Pavlou (2009), “Overcoming the J-shaped Distribution of Product Reviews," Communications of the ACM, 52 (10), 144-47. 
Hung, Kineta H., and Stella Yiyan Li (2007), "The Influence of eWOM on Virtual Consumer Communities: Social Capital, Consumer Learning and Behavioural Outcomes," Journal of Advertising Research, 47 (4), 485-95.

Jeong, EunHa, and SooCheong Shawn Jang (2011), "Restaurant Experiences Triggering Positive Electronic Word-of-Mouth (eWOM) Motivations," International Journal of Hospitality Management, 30 (2), 356-66.

Jones, Kiku, and Lori N.K. Leonard (2008), "Trust in Consumer-to-Consumer Electronic Commerce," Information \& Management, 45 (2), 88-95.

Kaplan, Andreas M., and Michael Haenlein (2010), "Users of the world, unite! The challenges and opportunities of Social Media," Business horizons, 53 (1), 59-68.

Kimmel, Allan J. and Philip J. Kitchen, (2014), "WOM and Social Media: Presaging Future Directions for Research and Practice," Journal of Marketing Communications, 20 (1-2), $5-20$.

Kuusela, Hannu, and Pallab Paul (2000), "A Comparison of Concurrent and Retrospective Verbal Protocol Analysis,” The American Journal of Psychology, 113 (3), 387-404.

------, Mark T. Spence, and Antti J. Kanto (1998), "Expertise Effects on Prechoice Decision Processes and Final Outcomes: A Protocol Analysis," European Journal of Marketing, $32(5 / 6), 559-76$.

Lee, A., Xu, Y., AND Hyde, K. F. (2013). "Factors influencing Investor Choice of Retirement Funds.” Journal of Financial Services Marketing, 18 (2), 137-51.

Lee, Mira, and Seounmi Youn (2009), "Electronic Word of Mouth (eWOM): How eWOM Platforms Influence Consumer Product Judgement," International Journal of Advertising, 28 (3), 473-99.

Li, Mengxiang, Liqiang Huang, Chuan-Hoo Tan, and Kwok-Kee Wei (2013), "Helpfulness of Online Product Reviews as Seen by Consumers: Source and Content Features," International Journal of Electronic Commerce, 17 (4), 101-36.

Liang, Ting-Peng, and Efraim Turban (2011-2012), "Introduction to the Special Issue Social Commerce: A Research Framework for Social Commerce," International Journal of Electronic Commerce, 16 (2), 5-13.

------, Yi-Ting Ho, Yu-Wen Li, and Efrain Turban (2011-2012), "What Drives Social Commerce: The Role of Social Support and Relationship Quality," International Journal of Electronic Commerce, 16 (2), 69-90.

Litvin, Stephen W., Ronald E. Goldsmith, and Bing Pan (2008), "Electronic Word-of-Mouth in Hospitality and Tourism Management," Tourism Management, 29 (3), 458-68.

MacManus, Richard (2012), “Out of Nowhere, TripAdvisor Becomes One of Facebook's Biggest Apps," Readwrite, June 29 (available at http://readwrite.com/2012/06/29/out-ofnowhere-tripadvisor-becomes-one-of-facebooks-biggest-apps). 
Mayzlin, Dina, Yaniv Dover, and Judith Chevalier (2012), "Promotional Reviews: An Empirical Investigation of Online Review Manipulation," Social Science Research Network, August 13 (http://papers.ssrn.com/sol3/papers.cfm?abstract id=2128860).

McCartney, Scott (2012), “The Big Flaws in Hotel Rankings,” The Wall Street Journal, April 10 , (available at http://www.wsj.com/articles/SB10001424052702304072004577323874046732602)

McKnight, D. Harrison, Charles J. Kacmar, and Vivek Choudhury, "Shifting Factors and the Ineffectiveness of Third Party Assurance Seals: A Two-Stage Model of Initial Trust in a Web Business," Electronic Markets 14 (3), 252 - 266.

Nielsen (2012), "State of the Media: The Social Media Report 2012," March 12 (available at http://www.nielsen.com/us/en/insights/reports/2012/state-of-the-media-the-social-media-report2012.html).

Nordin, Fredrik, and Christian Kowalkowski (2010), "Solutions Offerings: A Critical Review and Reconseptualisation," Journal of Service Management, 21 (4), 441-59.

Pan, Lee-Yun, and Jyh-Shen Chiou (2011), "How Much Can You Trust Online Information? Cues for the Perceived Trustworthiness of Consumer-generated Online Information," Journal of Interactive Marketing, 25 (2), 67-74.

Rubalcaba, Luis, Stefan Michel, Jon Sundbo, Stephen W. Brown, and Javier Reynoso (2012), "Shaping, Organizing, and Rethinking Service Innovation: A Multidimensional Framework," Journal of Service Management, 23 (5), 696-715.

Rui, Huaxia, Yizao Liu, and Andrew Whinston (2013), "Whose and What Chatter Matters? The Effect of Tweets on Movie Sales," Decision Support Systems, 55 (4), 863-70.

Saarijärvi, Hannu, Heikki Karjaluoto, and Hannu Kuusela (2013), "Customer Relationship Management: The Evolving Role of Customer Data," Marketing Intelligence \& Planning, 31 (6), 584-600.

Schindler, Robert M., and Barbara Bickart (2012), "Perceived Helpfulness of Online Consumer Reviews: The Role of Message Content and Style," Journal of Consumer Behaviour, 11 (3), 234-43.

Simonson, Itamar, and Emanuel Rosen (2014), "What Marketers Misunderstand About Online Reviews," Harvard Business Review, 92 (1/2), 23-25.

Smith, Donnavieve, Satya Menon, and K. Sivakumar (2005), "Online Peer and Editorial Recommendations, Trust, and Choice in Virtual Markets," Journal of Interactive Marketing, 19 (3), 15-37.

Stake, Robert E. (2005), "Qualitative Case Studies," in The Sage Handbook of Qualitative Research, Denzin, Norman K., and Yvonne S. Lincoln, eds, Thousand Oaks, CA: Sage: 443-66. 
Stake, Robert E. (1994), "Case studies", in Handbook of Qualitative Research, Denzin, Norman K., and Yvonne S. Lincoln, eds, Thousands Oaks, CA: Sage.

Steffes, Erin M., and Lawrence E. Burgee (2009), "Social Ties and Online Word of Mouth," Internet Research, 19 (1), 42-59.

Todd, Peter, and Izak Benbasat (1987), "Process Tracing Methods in Decision Support Systems Research: Exploring the Black Box,” MIS Quarterly, 11 (4), 493-512.

TripAdvisor, (2016), "TripAdvisor Fact Sheet," (available at https://www.tripadvisor.com/PressCenter-c4-Fact_Sheet.html).

Ugander, Johan, Brian Karrer, Lars Backstrom, and Cameron Marlow (2011), ”The Anatomy of the Facebook Social Graph," November 18 (available at http://arxiv.org/abs/1111.4503).

Wirtz, Jochen, and Patricia Chew (2002), "The Effects of Incentives, Deal Proneness, Satisfaction and Tie Strength on Word-of-Mouth Behavior," International Journal of Service Industry Management, 13 (2),141-62.

Wulff, Dirk U., Thomas T. Hills, and Ralph Hertwig (2015), "Online Product Reviews and the Description-Experience Gap," Journal of Behavioral Decision Making, 28 (3), 214 23.

Xie, Hui (Jimmy), Li Miao, Pei-Jou Kuo, and Bo-Yon Lee (2011), “Consumers' Responses to Ambivalent Online Hotel Reviews: The Role of Perceived Source Credibility and Predecisional Disposition," International Journal of Hospitality Management, 30 (2), 178-83.

Xue, Fei, and Joseph E. Phelps (2004), "Internet Facilitated Consumer-to-Consumer Communication: The Moderating Effect of Receiver Characteristics," International Journal of Internet Marketing and Advertising, 1 (2),121-36.

Yadav, Manjit S. (2010), "The Decline of Conceptual Articles and Implications for Knowledge Development," Journal of Marketing, 74 (1),1-19.

------, Kristine de Valck, Thorsten Hennig-Thurau, Donna L. Hoffman, and Martin Spann (2013), "Social Commerce: A Contingency Framework for Assessing Marketing Potential," Journal of Interactive Marketing, 27(4), 311-23.

You, Ya, Gautham G. Vadakkepatt, and Amit M. Joshi (2015), "A Meta-Analysis of Electronic Word-of-Mouth Elasticity,” Journal of Marketing, 79 (2),19-39. 
Table 1

Social eWOM Dimensions

\begin{tabular}{|l|l|}
\hline $\begin{array}{l}\text { Social eWOM } \\
\text { dimension }\end{array}$ & Defining characteristics \\
\hline $\begin{array}{l}\text { Intended } \\
\text { audience }\end{array}$ & $\begin{array}{l}\text { Non-public; limited and known audience; privacy; restricted } \\
\text { membership filters out opinions of unknown senders and eases } \\
\text { information search }\end{array}$ \\
\hline $\begin{array}{l}\text { Information } \\
\text { trustworthiness }\end{array}$ & $\begin{array}{l}\text { Information from known senders deemed more trustworthy: genuine, } \\
\text { not false information; enables better decision-making }\end{array}$ \\
\hline $\begin{array}{l}\text { Evaluation of } \\
\text { source }\end{array}$ & $\begin{array}{l}\text { Information prioritization; holistic evaluation of benefits; strength of } \\
\text { the relationship with the source (strong rather than weak ties); } \\
\text { receiver has knowledge of the source and their expertise; value of } \\
\text { information can be adjusted or weighted given knowledge of the } \\
\text { background of the content provider }\end{array}$ \\
\hline $\begin{array}{l}\text { Interpersonal } \\
\text { relationships }\end{array}$ & $\begin{array}{l}\text { Social interaction, not just decision-making; comparison and } \\
\text { competition; perception of self in the social network; new insight into } \\
\text { the members of the social network; building social connections }\end{array}$ \\
\hline
\end{tabular}


Figure 1

Study Design

RESEARCH PURPOSE:

DATA GENERATION

- CASE STUDY RESEARCH SETTI

- VERBAL PROTOCOL METHOD - SEMI-STRUCTURED INTERVIEW
- FOCUS GROUP INTERVIEWS

DATA ANALYSIS

RESULTS

INTRODUCE AND UNCOVER 
Figure 2

Converting Anonymous eWOM into Social eWOM

\begin{tabular}{|c|c|c|c|}
\hline $\begin{array}{l}\text { ENABLING eWOM } \\
\text { GENERATION } \\
\text { Developing social media } \\
\text { applications that get } \\
\text { and allow consumers } \\
\text { to share their } \\
\text { experiences. }\end{array}$ & $\begin{array}{c}\text { eWOM } \\
\text { GENERATION } \\
\text { Consumers writing } \\
\text { their reviews and/or } \\
\text { giving feedback. }\end{array}$ & $\begin{array}{l}\text { CONVERTING } \\
\text { anoymous eWOM } \\
\text { into social eWOM } \\
\text { Linking eWOM with } \\
\text { social media } \\
\text { platforms. }\end{array}$ & $\begin{array}{l}\text { CONSUMER } \\
\text { DECISION-MAKING } \\
\text { Using applications and/or } \\
\text { social media platforms to } \\
\text { target social eWOM for } \\
\text { those who need } \\
\text { information for } \\
\text { their decision-making. }\end{array}$ \\
\hline
\end{tabular}


Figure 3

Anonymous eWOM to Social eWOM Continuum

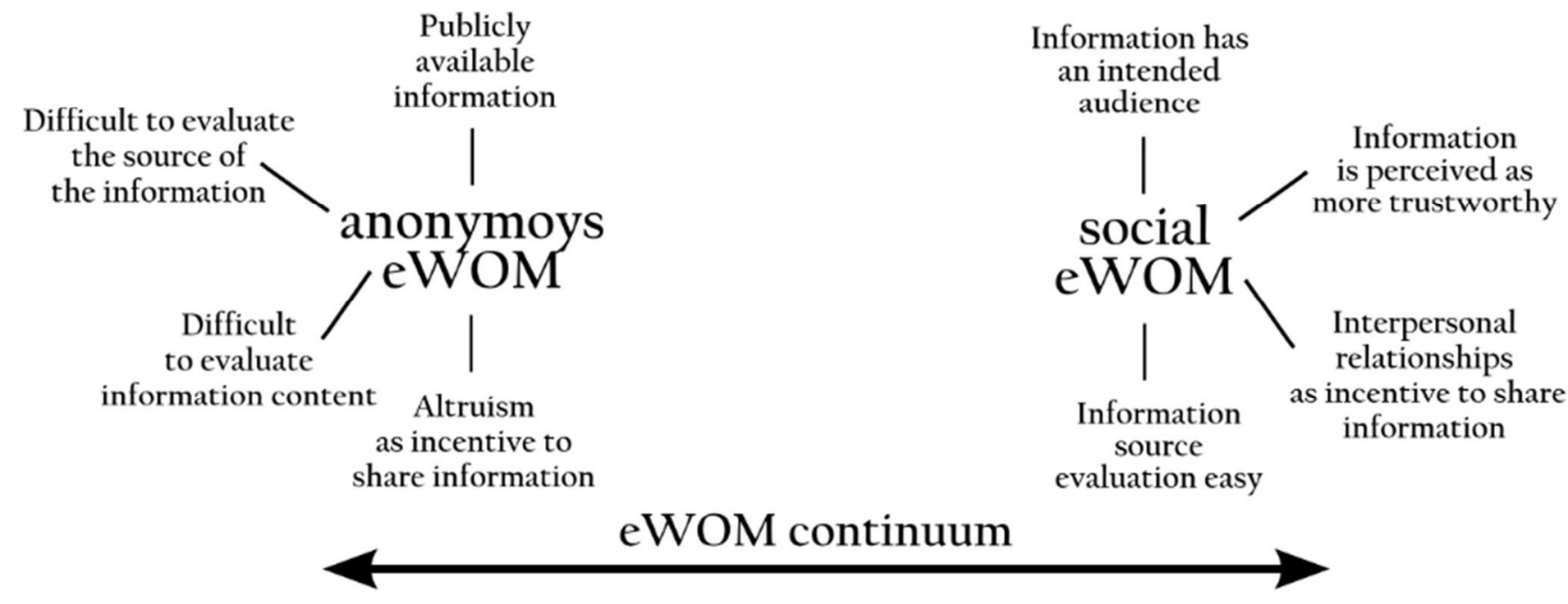


APPENDIX 1:

Interview Informants

\begin{tabular}{|l|c|c|}
\hline Informant & Age & $\begin{array}{c}\text { Interview } \\
\text { duration }\end{array}$ \\
\hline Female 1 & 24 & $60 \mathrm{~min}$ \\
\hline Female 2 & 24 & $75 \mathrm{~min}$ \\
\hline Male 1 & 23 & $50 \mathrm{~min}$ \\
\hline Female 3 & 24 & $45 \mathrm{~min}$ \\
\hline Female 4 & 25 & $55 \mathrm{~min}$ \\
\hline Male 2 & 27 & $50 \mathrm{~min}$ \\
\hline Female 5 & 21 & $50 \mathrm{~min}$ \\
\hline Male 3 & 25 & $65 \mathrm{~min}$ \\
\hline Male 4 & 25 & $45 \mathrm{~min}$ \\
\hline Male 5 & 25 & $50 \mathrm{~min}$ \\
\hline
\end{tabular}




\section{APPENDIX 2:}

Focus Group Informants

\begin{tabular}{|l|l|l|}
\hline $\begin{array}{l}\text { Focus } \\
\text { group }\end{array}$ & Participants & Duration \\
\hline & $\begin{array}{l}\text { Male, 32 } \\
\text { Male, 22 } \\
\text { Female, 22 } \\
\text { Female, 20 } \\
\text { Female, 25 }\end{array}$ & $1 \mathrm{~h} 40 \mathrm{~min}$ \\
\hline \multirow{2}{*}{3} & $\begin{array}{l}\text { Male, 29 } \\
\text { Female, 21 } \\
\text { Female, 22 } \\
\text { Female, 23 }\end{array}$ & $1 \mathrm{~h} 28 \mathrm{~min}$ \\
\hline \multirow{3}{*}{$\begin{array}{l}\text { Female, 25 } \\
\text { Female, 26 } \\
\text { Female, 22 } \\
\text { Female, 20 }\end{array}$} & $1 \mathrm{~h} 23 \mathrm{~min}$ \\
\hline 4 & $\begin{array}{l}\text { Male, 22 } \\
\text { Female, 21 } \\
\text { Female, 22 }\end{array}$ & $1 \mathrm{~h} 25 \mathrm{~min}$ \\
\hline
\end{tabular}




\section{APPENDIX 3:}

\section{Illustrative Quotes}

\begin{tabular}{|c|c|c|}
\hline $\begin{array}{l}\text { Social eWOM } \\
\text { dimension }\end{array}$ & $\begin{array}{l}\text { Defining } \\
\text { characteristic }\end{array}$ & Illustrative quotes \\
\hline \multirow[t]{4}{*}{$\begin{array}{l}\text { Intended } \\
\text { audience }\end{array}$} & Non-public & $\begin{array}{l}\text { The one time we were going to Thailand I read all } \\
\text { kinds of blogs and traveling websites and such, but } \\
\text { in the end, I got the best tips from my friends. From } \\
\text { them, I got information that people don't generally } \\
\text { want to share with everybody else, for example, } \\
\text { that they wouldn't have gone to this specific island } \\
\text { they had been to this time but would have picked } \\
\text { another one instead. (F2, SSI) }\end{array}$ \\
\hline & $\begin{array}{l}\text { Limited and known } \\
\text { audience }\end{array}$ & $\begin{array}{l}\text { When people write these reviews under their own } \\
\text { names and share them with their buddies, they are } \\
\text { at least not trolling like many writers on the web, } \\
\text { like, for example, this one friend of mine knows } \\
\text { that I could be reading these, so you can see that he } \\
\text { has thought about it a bit. (M2, SSI) }\end{array}$ \\
\hline & Privacy & $\begin{array}{l}\text { Oh, okay, I never realized that all my friends can } \\
\text { see these. Or I mean that it's so easy. Maybe I } \\
\text { should do a little scan on what I've shared here. I } \\
\text { mean, I don't want everyone to know what I've } \\
\text { done. (M5, VP) }\end{array}$ \\
\hline & $\begin{array}{l}\text { Eases information } \\
\text { search }\end{array}$ & $\begin{array}{l}\text { To some extent, it narrows down information, like, } \\
\text { if you think about how much information there is in } \\
\text { the world and how much stuff you can look up } \\
\text { online. I just have to narrow down the information } \\
\text { somehow, like what will I even look for and what } \\
\text { kind of places are worth going to for me. It's just } \\
\text { such an easy filter that there are people [I know] } \\
\text { who have traveled there a lot, so you can look up } \\
\text { what they have done and then check out more info } \\
\text { on what I'm interested in. (F4, SSI) }\end{array}$ \\
\hline \multirow[t]{3}{*}{$\begin{array}{l}\text { Information } \\
\text { trustworthiness }\end{array}$} & $\begin{array}{l}\text { Information source } \\
\text { trustworthiness }\end{array}$ & $\begin{array}{l}\text { I'll get a reliable source since I can then talk to this } \\
\text { person directly without anyone in between. ... } \\
\text { Because I know this guy anyway, so he wouldn't } \\
\text { dare lie to me at least. (F2, SSI) }\end{array}$ \\
\hline & $\begin{array}{l}\text { Information about the } \\
\text { background of the } \\
\text { source }\end{array}$ & $\begin{array}{l}\text { If it's a friend who has written the review so from } \\
\text { that I know best because in that case I can kind of } \\
\text { assess the review and compare it to this person's } \\
\text { style and habits and character. (F1, SSI) }\end{array}$ \\
\hline & $\begin{array}{l}\text { Enablement of better } \\
\text { decisions }\end{array}$ & $\begin{array}{l}\text { That [advice from a friend] definitely added that } \\
\text { little something to my trip. For example, thanks to } \\
\text { him, we found two or three really great restaurants, }\end{array}$ \\
\hline
\end{tabular}




\begin{tabular}{|c|c|c|}
\hline & & $\begin{array}{l}\text { I mean awesome! So that this time it was good to } \\
\text { get the expert's advice. It was useful. (M2, SSI) }\end{array}$ \\
\hline \multirow[t]{4}{*}{$\begin{array}{l}\text { Evaluation of } \\
\text { source }\end{array}$} & $\begin{array}{l}\text { Information } \\
\text { prioritization }\end{array}$ & $\begin{array}{l}\text { If it's a close friend of mine, I'll ask her on } \\
\text { Facebook or I could even give her a call, or if I see } \\
\text { her, so I'll know if a place is even worth going to, } \\
\text { and what she says about the place in general. (F2, } \\
\text { SSI) }\end{array}$ \\
\hline & $\begin{array}{l}\text { Holistic evaluation of } \\
\text { benefits }\end{array}$ & $\begin{array}{l}\text { Like this one here, what my friend is saying, is a } \\
\text { really good addition to what I've read elsewhere. } \\
\text { I'd check this place out for sure when going there. } \\
\text { Like, my point is that your friends usually give you } \\
\text { great tips, and they complement my planning. (M2, } \\
\text { VP) }\end{array}$ \\
\hline & $\begin{array}{l}\text { Perception of the } \\
\text { source's profile }\end{array}$ & $\begin{array}{l}\text { I wouldn't ask just anyone of my friends 'cause I } \\
\text { have these friends who have to go to a five-star } \\
\text { luxury hotel, and they spend their entire holiday } \\
\text { there ... if someone just goes through the basic } \\
\text { tourist spots and otherwise hangs out at the hotel, } \\
\text { then it's no use asking them anything. More than } \\
\text { that, I choose budget travelers who want to see } \\
\text { more than just the touristy stuff, like, for example, } \\
\text { meet the locals. (M1, SSI) }\end{array}$ \\
\hline & $\begin{array}{l}\text { Source's perceived } \\
\text { expertise }\end{array}$ & $\begin{array}{l}\text { When I go to, London, for example, I ask for tips } \\
\text { from someone who goes there a lot, like J_, for } \\
\text { example. She goes there like four times a year. (F5, } \\
\text { SSI) }\end{array}$ \\
\hline \multirow[t]{2}{*}{$\begin{array}{l}\text { Interpersonal } \\
\text { relationships }\end{array}$} & Social interaction & $\begin{array}{l}\text { I really like it that they ask me of all people. That } \\
\text { they see me as the kind of person who has traveled } \\
\text { a lot ... So, it doesn't annoy me in any way. And } \\
\text { it's really nice to really help someone and if I feel } \\
\text { that some destination is definitely worth visiting, I } \\
\text { really like telling others about it. So I like to give } \\
\text { people tips and stuff. (F3, SSI) }\end{array}$ \\
\hline & $\begin{array}{l}\text { Strengthening the } \\
\text { social relationship }\end{array}$ & $\begin{array}{l}\text { For example, I like when people ask me those kinds } \\
\text { of things so that I can like help someone so that this } \\
\text { person then gets kind of like the same feeling about } \\
\text { it. ... I like giving my friend a reason to think back } \\
\text { about the trip if she'd get the good feeling again } \\
\text { when looking back on it all. ... [I]t cheers up both } \\
\text { of us in some way. (F3, SSI) }\end{array}$ \\
\hline
\end{tabular}




\begin{tabular}{|c|c|}
\hline $\begin{array}{l}\text { Comparison and } \\
\text { competition }\end{array}$ & $\begin{array}{l}\text { It's great that so many people use it and have } \\
\text { clicked on all the places they've been to, and so } \\
\text { you feel like, damn it, I still want to go to places, } \\
\text { too. And like if a lot of my friends have been to } \\
\text { some place. So you start feeling a little competitive. } \\
\text { (M1, SSI) }\end{array}$ \\
\hline $\begin{array}{l}\text { Perception of self in } \\
\text { the social network }\end{array}$ & $\begin{array}{l}\text { I at least feel like, shoot, I've traveled so little. That } \\
\text { all my friends have seen so much more. I guess I } \\
\text { should, too. (M5, VP) }\end{array}$ \\
\hline $\begin{array}{l}\text { New information and } \\
\text { perception about the } \\
\text { members of the social } \\
\text { network }\end{array}$ & $\begin{array}{l}\text { It's really interesting to see where your friends } \\
\text { have been to. Like, it's nice to know who the heavy } \\
\text { travelers are. And, like, what kind of destinations } \\
\text { they go to. Like, if a friend of mine travels to some } \\
\text { exotic places so it does tell me something about } \\
\text { that person for sure. (F3, SSI) }\end{array}$ \\
\hline $\begin{array}{l}\text { Building social } \\
\text { connections }\end{array}$ & $\begin{array}{l}\text { I think the good thing here is that you can see } \\
\text { friends of your friends, too. Like, once I saw on } \\
\text { Facebook that a friend of mine had commented on } \\
\text { some picture her friend had taken on a trip, so } \\
\text { that's really useful because then you know you can } \\
\text { drop them a line or something as you know they've } \\
\text { been to this place. (F5, SSI) }\end{array}$ \\
\hline
\end{tabular}

